\title{
SISTEM PENDUKUNG KEPUTUSAN PENERIMAAN CALON MAHASISWA BARU JALUR PRESTASI DI SEKOLAH TINGGI TEKNOLOGI ADISUTJIPTO MENGGUNAKAN SIMPLE MULTI ATTRIBUTE RATING TECHNIQUE
}

\section{Anton Setiawan Honggowibowo}

Teknik Informatika

Sekolah Tinggi Teknologi Adisutjipto

Jalan Janti Blok R Lanud Adisutjipto, Yogyakarta

anton_s_h@yahoo.com

\begin{abstract}
In the era of globalization, educational institutions are required to follow the development of information technology. Information technology required and can be applied as a decision support tool managerial activities at the college. This research aims to develop a decision support system for the Sekolah Tinggi Teknologi Adisutjipto (STTA), namely the acceptance of new students, especially the path of achievement, using the Simple Multi Attribute Rating Technique of Web-based, wherein the method is choosing alternative criteria that have value and weight has been determined, getting the new students he deserves. Based on the results of testing the system, it was concluded that the method is Simple Multi Attribute Rating Technique is effective enough to be applied in determining the admission of new students in STTA.
\end{abstract}

Keywords: information technology, decision support systems, simple multi attribute rating technique.

\section{Abstrak}

Pada era globalisasi, institusi pendidikan dituntut untuk mengikuti perkembangan teknologi informasi. Teknologi informasi diperlukan dan dapat diterapkan sebagai alat penunjang keputusan suatu kegiatan manajerial di perguruan tinggi. Penelitian ini bertujuan untuk membangun sistem pendukung keputusan untuk Sekolah Tinggi Teknologi Adisutjipto (STTA), yaitu mengenai penerimaan calon mahasiswa baru khususnya jalur prestasi, menggunakan metode Simple Multi Attribute Rating Technique berbasis Web, dimana metode ini memilih alternatif kriteria yang mempunyai nilai dan bobot yang telah ditentukan, untuk mendapatkan hasil calon mahasiswa baru yang layak diterima. Berdasarkan hasil pengujian sistem, didapatkan kesimpulan bahwa Metode Simple Multi Attribute Rating Technique cukup efektif untuk diterapkan dalam menentukan penerimaan calon mahasiswa baru di STTA.

Kata kunci: information technology, decision support systems, simple multi attribute rating technique. 


\section{Pendahuluan}

Pada era globalisasi, teknologi informasi semakin berkembang pesat, untuk itu banyak institusi pendidikan atau sekolah tinggi dituntut untuk mengikuti perkembangan teknologi yang berguna sebagai alat pelayanan. Dalam perkembangan teknologi komputer memunculkan pemahaman baru akan pentingnya kebutuhan informasi yang cepat dan akurat, sehingga keputusan segera dapat diambil dalam waktu yang relatif singkat.

Sekolah Tinggi Teknologi Adisutjipto (STTA) adalah salah satu perguruan tinggi di Yogyakarta yang memiliki banyak calon mahasiswa baru yang akan mendaftar sebagai mahasiswa baru di STTA. Para calon mahasiswa baru memilih jalur pendaftaran sesuai kriteria atau persyaratan dari Kampus STTA. Kriteria jalur pendaftaran dapat berupa jalur prestasi, jalur reguler dan jalur keluarga TNI/ POLRI. Oleh karena itu perlu dibuat aplikasi untuk menunjang atau mendukung keputusan menentukan kriteria calon mahasiswa baru yang akan menempuh jenjang Strata 1 (S1) di STTA sesuai jurusan yang di inginkan oleh calon mahasiswa baru tersebut. Dalam penelitian ini akan mengkhususkan kriteria penerimaan calom mahasiswa baru dari jalur prestasi.

Dalam menentukan kriteria mahasiswa baru di STTA digunakan metode Simple Multi Atribute Rating Technique (SMART). Metode ini merupakan metode pembobotan yang digunakan untuk menghitung bobot kriteria dari calon mahasiswa baru yang akan menempuh jenjang S1 di STTA.

\section{Metodologi Penelitian}

\subsection{Metode SMART}

SMART merupakan suatu model pengambil keputusan yang komprehensif dengan memperhitungkan hal- hal yang bersifat kualitatif dan kuantitatif. Dalam model pengambilan keputusan dengan SMART pada dasarnya berusaha menutupi setiap kekurangan dari modelmodel tanpa komputerisasi sebelumnya.

\subsection{Gambaran Metode SMART}

Model fungsi utiliti linear yang digunakan oleh SMART adalah seperti Persamaan 1:

$$
\operatorname{Maximize} \sum_{j=1}^{i k} w_{j}, u_{0 j}, w_{i}=1, \ldots, n
$$

Di mana :

- $\quad \mathrm{W} j$ adalah nilai pembobotan kriteria ke-j dari $k$ kriteria.

- $\quad$ U $i j$ adalah nilai utility alternatif $i$ pada kriteria $j$.

- Pemilihan keputusan adalah mengidentifikasi mana dari $n$ alternatif yang mempunyai nilai fungsi terbesar.

- Nilai fungsi ini juga dapat digunakan untuk merangking $n$ alternatif

Langkah - langkah menerapkan metode SMART :

1. Identifikasi masalah keputusan.

2. Identifikasi kriteria-kriteria yang digunakan dalam membuat keputusan.

3. Mengidentifikasi alternatif-alternatif yang akan dievaluasi. 
4. Melakukan peringkat terhadap kedudukan kepentingan kriteria. alternatif.

5. Memberi bobot pada setiap kriteria berdasarkan kepentingan terhadap suatu

6. Menghitung normalisasi bobot kriteria, Bobot yang diperoleh akan dinormalkan dimana bobot setiap kriteria yang diperoleh akan dibagikan dengan hasil jumlah setiap bobot kriteria.

7. Mengembangkan single-attribute utilities yang mencerminkan seberapa baik setiap alternatif dilihat dari setiap kriteria. Tahap ini adalah memberikan suatu nilai pada semua kriteria untuk setiap alternatif. Dalam bidang ini seorang ahli memperkirakan nilai alternatif dalam skala $0-100$.

8. Menghitung penilaian utilitas terhadap setiap alternatif.

9. Memutuskan, nilai utilitas dari setiap alternatif akan diperoleh langkah 8. Jika suatu alternatif tunggal yang akan dipilih, maka pilih alternatif dengan nilai utilitas terbesar.

Dalam metode ini dilihat beberapa parameter yang menjadi penentu keputusan tersebut. Parameter tersebut mempunyai jarak nilai dan bobot yang berbeda-beda. Nilai tersebut nantinya akan menjadi penentu keputusan yang diambil. Pembobotan metode tersebut dapat dilihat pada Tabel 1.

Tabel 1. Pembobotan Metode Smart

\begin{tabular}{|l|c|l|}
\hline KRITERIA PENILAIAN & NILAI & BOBOT \\
\hline KRITERIA JALUR PRESTASI & & \\
\cline { 1 - 2 } Nilai kelulusan diatas rata -rata & 90 & Ditentukan admin \\
Pembayaran sesuai jalur prestasi & 70 & \\
Rapot SMA/ SMK grade tinggi & 80 & \\
\hline
\end{tabular}

Berdasarkan Tabel 1 bobot yang ditentukan admin memiliki skala 10 hingga 100 . Pada setiap poin kriteria sebagai pilihan input-an untuk admin yang berfungsi memberi nilai alternatif jalur masuk di kampus STTA berdasarkan nilai Tabel 1 adalah contoh nilai yang disediakan oleh sistem. Untuk menghitung nilai akhirnya harus dilakukan normalisasi terhadap bobot yang ditentukan admin dengan cara membagi bobot yang diinputkan admin dalam satu kriteria dengan seluruh jumlah bobot yang diinputkan oleh admin tersebut. Dalam hal ini dirancang agar total bobot yang dimasukan harus bernilai 100. Berikut perhitungan untuk mencari normalisasi pada kriteria jalur prestasi :
a. Nilai kelulusan diatas rata - rata $=\frac{\text { Bobot raxa-raxakelulugan }}{\text { Total kegeluruhan bobot }}$
b. Pembayaran jalur prestasi $=\frac{\text { Eobot perzbayaran jalur prestasi }}{\text { Total keseluruhen bobot }}$
c. Raport sma grade tinggi $=\frac{\text { Bobot raport }}{\text { Total Keselueuhan bobot }}$

Kemudian setelah diketahui normalisasi kriteria jalur prestasi dari bobot yang sudah ditentukan jumlahnya oleh user, maka untuk menghitung hasil dari perolehan metode 
SMART yaitu dengan mengkalikan bobot kriteria yang sudah di normalisasi dengan nilai utility yang sudah ditentukan oleh sistem.

Nilai Akhir Jalur Prestasi $=\quad$ (normalisasi rata- rata kelulusan $\times$ value rata-rata kelulusan $)+($ normalisasi pembayaran jalur prestasi $\times$ value pembayaran jalur prestasi) + (normalisasi nilai raport $\times$ value nilai raport)

Berdasarkan nilai akhir tersebut ditentukan hasilnya dengan cara mengambil satu alternatif yang memiliki skor terbesar untuk menentukan layak tidaknya calon mahasiswa tersebut menjadi mahasiswa di kampus STTA, maka alternatif tersebutlah yang menjadi rekomendasi. Nilai fungsi metode SMART ini juga dapat digunakan untuk merangking beberapa alternatif. Dalam penggunaan metode SMART ini sangatlah fleksibel dikarenakan apabila ingin memilih hasil lebih dari satu alternatif, maka pengguna aplikasi ini dapat memberikan sendiri batasan minimal nilai untuk menentukan kelayakan alternatif yang ada.

\subsection{Sistem Pendukung Keputusan}

Sistem Pendukung Keputusan (SPK) atau Decision Support System (DSS) adalah sebuah sistem yang mampu memberikan kemampuan pemecahan masalah maupun kemampuan pengkomunikasian untuk masalah dengan kondisi semi terstruktur dan tak terstruktur. Sistem ini digunakan untuk membantu pengambilan keputusan dalam situasi semi terstruktur dan situasi yang tidak terstruktur, di mana tak seorangpun tahu secara pasti bagaimana keputusan seharusnya dibuat (Turban, 2001).

SPK bertujuan untuk menyediakan informasi, membimbing, memberikan prediksi serta mengarahkan kepada pengguna informasi agar dapat melakukan pengambilan keputusan dengan lebih baik.

\section{Hasil dan Pembahasan}

\subsection{Diagram Kontek Penerimaan Mahasiswa Baru Pada STTA}

Diagram kontek Sistem Pendukung Keputusan Penerimaan Calon Mahasiswa Baru Pada Sekolah Tinggi Teknologi Adisutjipto, diilustrasikan pada Gambar 1.

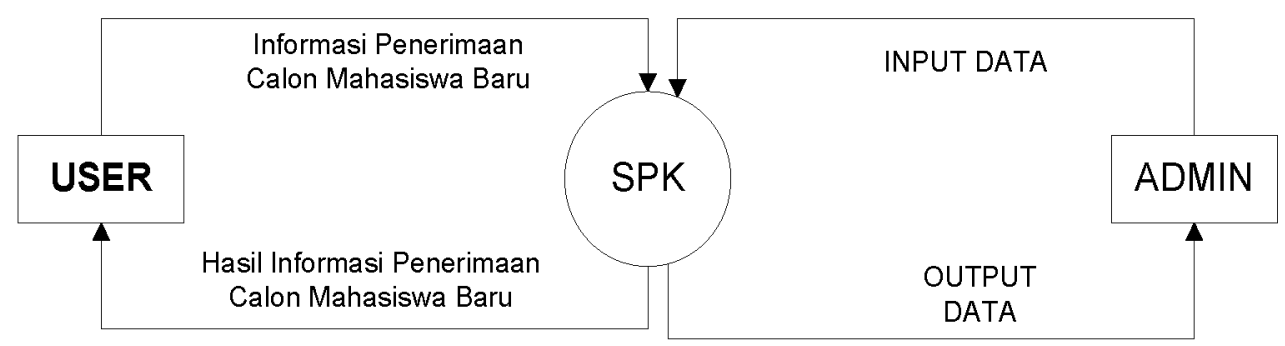

Gambar 1. Diagram Kontek

\subsection{Diagram Alir Data Level 1}

Aliran data dan detil proses-proses yang diintegrasikan ke dalam sistem digambarkan dalam diagram alir data level 1 yang merupakan turunan dari diagram kontek, ditunjukan pada Gambar 2. 


\subsection{Tampilan Jurusan}

Tampilan ini menyajikan kategori dari 5 jurusan sebagai sub menu berdasarkan masing-masing kriteria yang ada untuk calon mahasiswa baru jika pengguna tersebut memilih pilihan jurusan maka pengguna dapat melihat data mahasiswa dan untuk melihat hasil perhitungan SPK dengan metode SMART. Gambar tampilan ini dapat diilustrasikan pada Gambar 3.

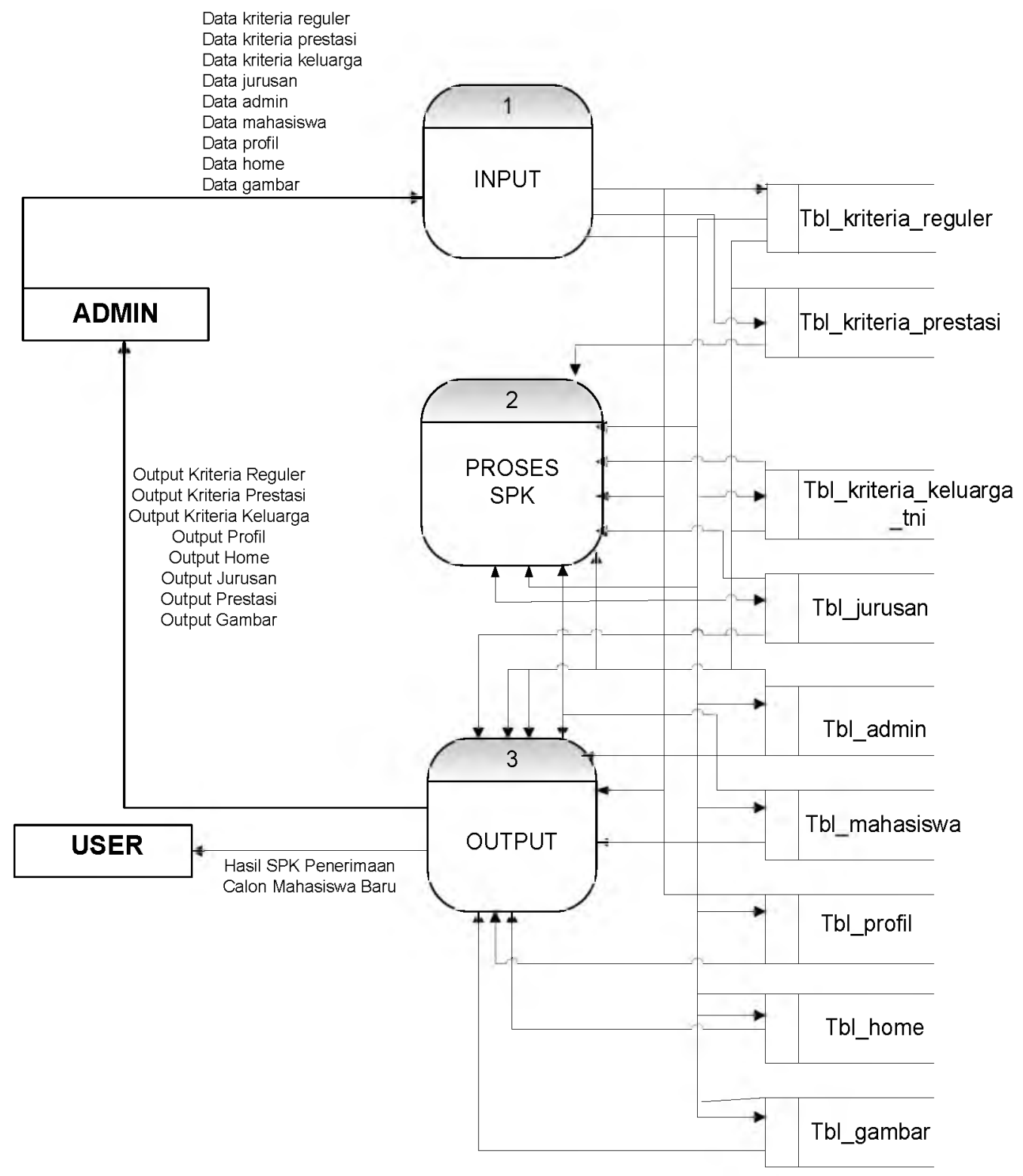

Gambar 2. Diagram Alir Data Level 1 


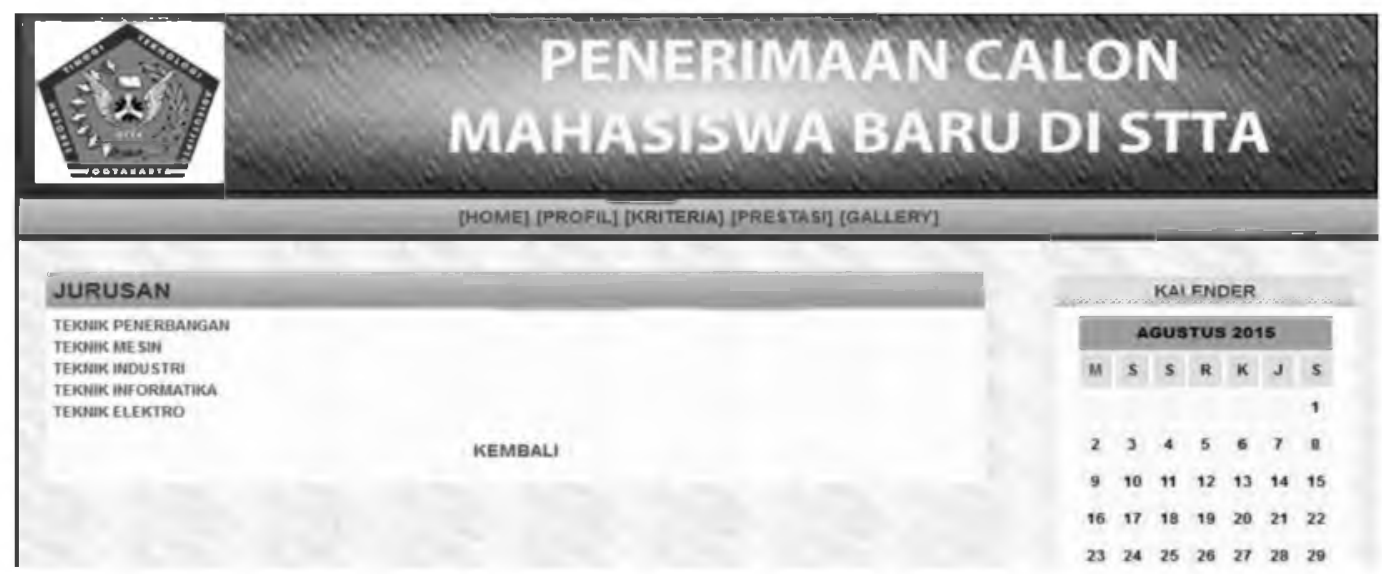

Gambar 3 Tampilan Halaman jurusan

\subsection{Hasil Perhitungan SPK Kriteria Prestasi}

Tampilan ini berisi data lengkap dari calon mahasiswa baru sesuai jalur prestasi dan menyajikan perhitungan hasil SPK dengan metode SMART di mana data ini berfungsi untuk menilai tiap calon mahasiswa baru berdasarkan atribut kriteria prestasi yang ditetapkan sebagai syarat untuk menunjukkan layak tidaknya calon mahasiswa baru tersebut menjadi mahasiswa di kampus STTA. Gambar tampilan diilustrasikan pada Gambar 4.

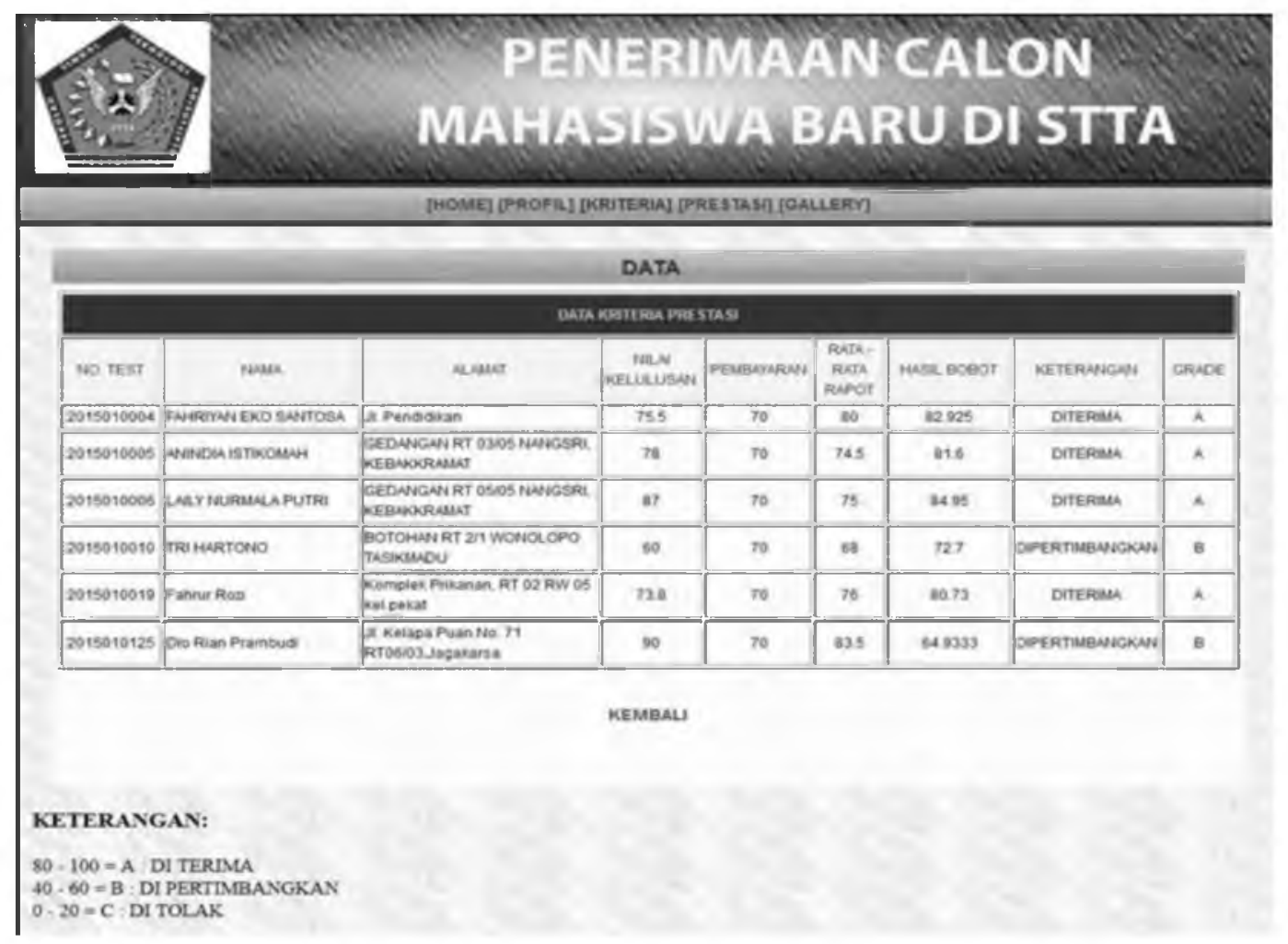

Gambar 4. Tampilan Halaman Hasil Perhitungan SPK Kriteria Prestasi 
Hasil pengujian dengan program dapat dilihat pada Gambar 4 di mana sebagai contoh menunjukkan nama Fahriyan Eko Santosa calon mahasiswa melalui jalur prestasi untuk dihitung atribut kriterianya yaitu: nilai kelulusan 75,5 ; pembayaran 70 dan rata- rata rapot 80 dengan nilai bobot yang sudah dinormalisasi dari tiga atribut kriteria adalah nilai kelulusan bobot $35 \%$, pembayaran bobot $35 \%$ dan rata-rata rapot bobot $40 \%$ mendapatkan hasil 82,925 menunjukkan diterima sebagai mahasiswa sesuai grade nilai yang telah ditentukan, sedangkan perhitungan menggunakan persamaan (1) manualnya adalah sebagai berikut:

Normalisasi Jalur Prestasi

a. Nilai kelulusan djatas rata - rata $=\frac{\text { Bobot rata-ratakelulusen }}{\text { Total keseluruhan bobot }}=\frac{35}{100}=0.35$

b. Pembayaran jalur prestasi $=\frac{\text { Bobot penbayaran jalur prestazi }}{\text { Total keseluruhan bobot }}=\frac{35}{100}=0.35$

c. Raport sma grade tinggi $=\frac{\text { Bobot raport }}{\text { Total kegeluruhen bobot }} x=\frac{40}{100}=0.40$

Nilai Akhir Jalur Prestasi $=$ (normalisasi rata- rata kelulusan $\times$ value rata-rata kelulusan $)+$ (normalisasi pembayaran jalur prestasi $\times$ value pembayaran jalur prestasi) + (normalisasi nilai raport $\times$ value nilai raport).

Jadi perhitungan hasil akhir adalah :

$75,5 \times 0,35+70 \times 0,35+80 \times 0,40=82,925$

Hasil perhitungan manual menggunakan Persamaan 1 dibandingkan dengan hasil perhitungan dari program aplikasi menampilkan hasil yang sama.

\section{Penutup}

\subsection{Kesimpulan}

Berdasarkan hasil analisis yang dilakukan dengan mengunakan metode simple multi attribute rating technique maka dapat diambil beberapa kesimpulan sebagai berikut.

1. Metode simple multi attribute rating technique cukup efektif untuk diterapkan dalam menentukan penerimaan calon mahasiswa baru jalur prestasi di STTA sesuai dengan uji sistem yang dilakukan.

2. Sistem yang dibangun sebagai sistem pendukung keputusan dapat membantu pihak pimpinan STTA dalam menentukan calon mahasiswa baru jalur prestasi.

\subsection{Saran}

Berdasarkan analisis sistem diketahui cara kerja sistem sehingga didapat saran-saran untuk pengembangan aplikasi ini selanjutnya. Saran-saran pengembangan sistem ini antara lain: membangun aplikasi untuk menentukan calon mahasiswa dengan menggunakan metode yang lain. 


\section{Daftar Pustaka}

Bin Ladjamudin, A., 2005, Analisis Dan Desain Sistem Informasi, Graha Ilmu, Yogyakarta. Hartono, Jogiyanto, 2005, Basis Dat $a$, Gava Media, Yogyakarta.

Kasie, Fentahun Moges, 2013, Combining Simple Multiple Attribute Rating Technique and Analytical Hierarchy Process for Designing Multi-Criteria Performance Measurement Framework, Global Journal of Researches in Engineering Industrial Engineering, Volume 13, Issue 1, Version 1.0, Global Journals Inc, USA.

Situmeang, Mesdina, 2015, Perancangan Aplikasi Penilaian Hasil Kinerja Dosen Terbaik Dengan Metode Simple Multi Attribute Rating Technique Studi Kasus : AKPER Yayasan Binalita Sudama Medan. Jurnal Ilmiah Pelita Informatika Budi Darma, Vol. IX, No. 1, Medan.

Supriana, I Wayan, 2012, Sistem Pendukung Keputusan Dalam Pemilihan Tempat Kost Dengan Metode Pembobotan (Studi Kasus : Sleman Yogyakarta), Jurnal Ilmu Komputer, Volume 5, No 2.

Turban, Efraim \& Aronson, Jay E, 2001, Decision Support Systems and Intelligent Systems, 6th edition. Prentice Hall: Upper Saddle River, NJ. 